خصائص الدقيق وجودة الخبز الناتج من خلط دقيق الكينوا بدقيق القمح

$$
\begin{aligned}
& \text { عبد المجيد بجاش عبد الله، جلال أحمد فضل، خالد محمد عساج } \\
& \text { قسم علوم وتقنية الأغذية. كلية الزراعة. جامعة صنعاء- اليمن }
\end{aligned}
$$

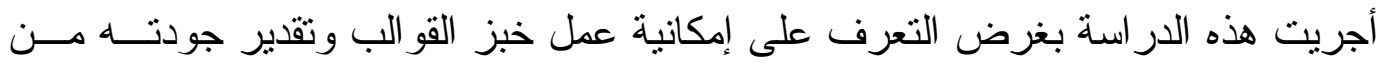

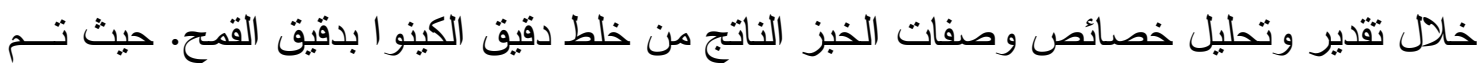

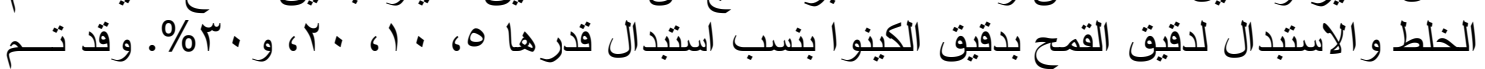

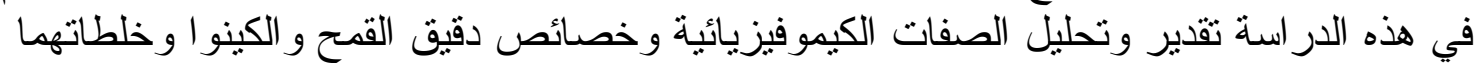

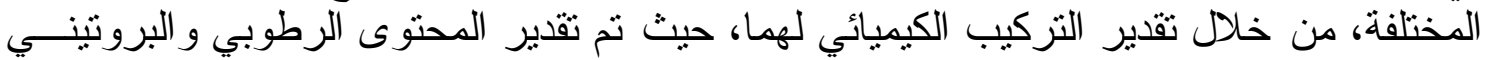

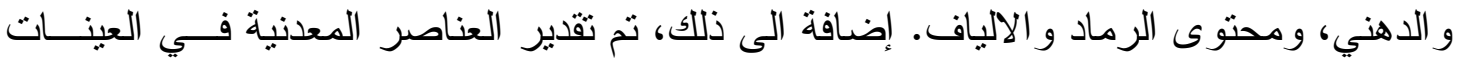

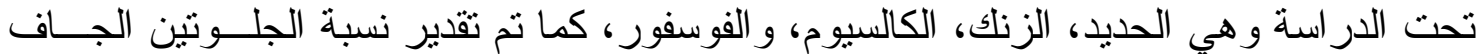

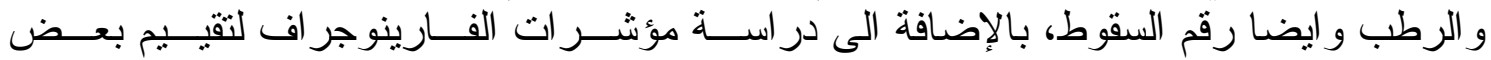

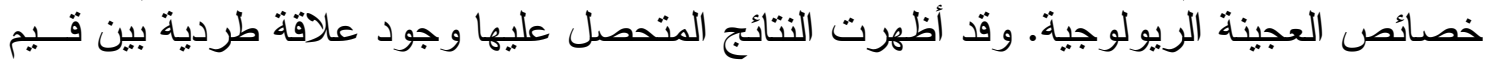

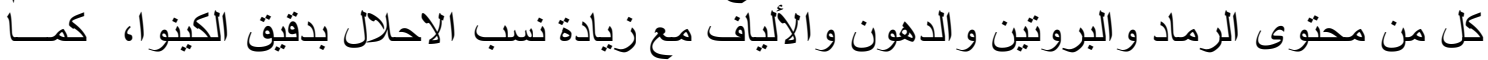

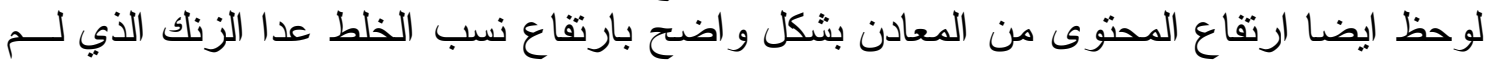
يظهر أي فروق معنوية في كل العينات.

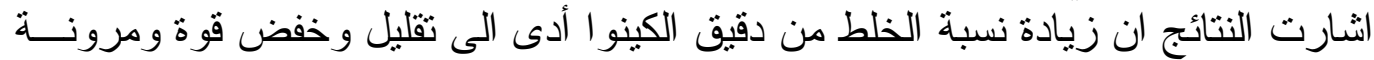

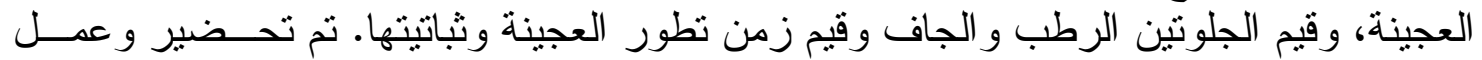

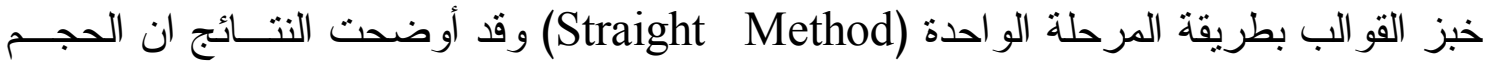

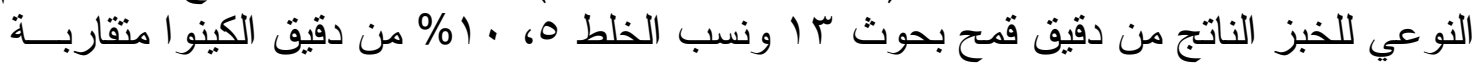

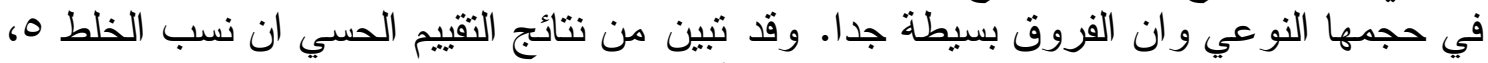

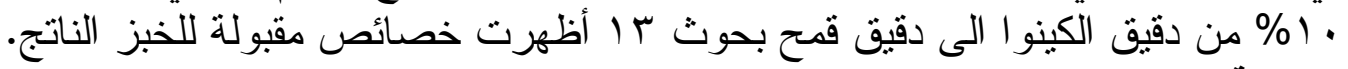

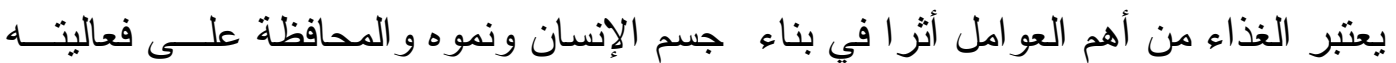

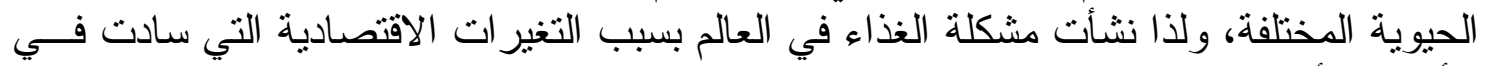

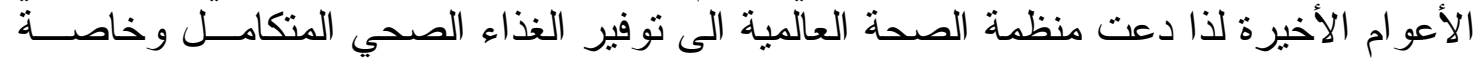

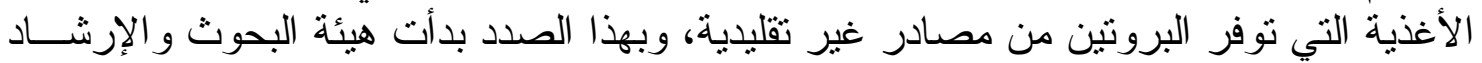

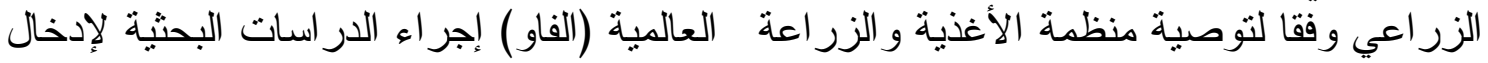

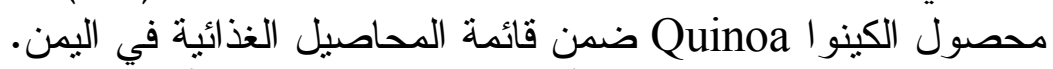

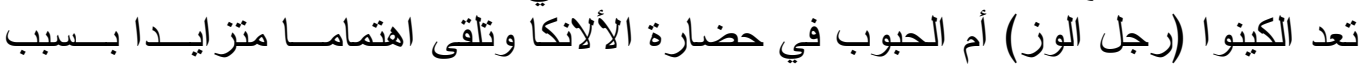

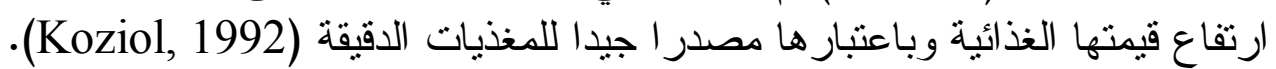

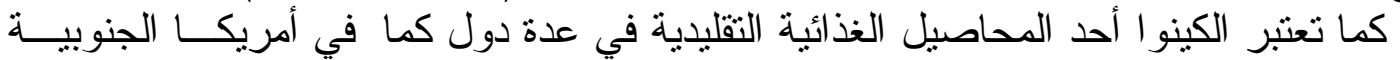

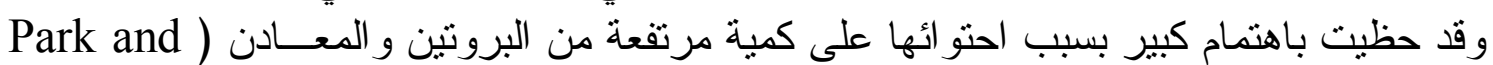

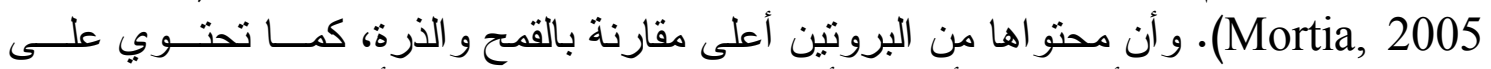

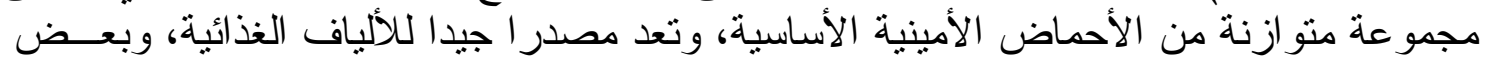

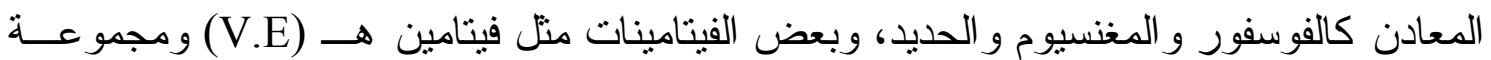
فيتامينات ب (Konishi et al., 2004 and Wright et al., 2002) (B. (B. 
تم در اسة حبوب الكينو ا من قبل عدد من الباحثين و استخدامها في انتاج منتجات مختلفــة مـن الخبـز و الكيــاك (Chauhan et al., 1992; Lorenz \& Coulter, 1991and Been \& Fellers, 1982

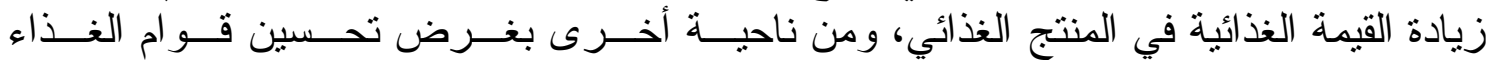
(Tömösközi et al., 1994 and Bajkai et al., 1996) بروتيناتها تتتمي إلى مجموعة الألبيومينات القابلة للذوبان في الماء و الجلوبيولينات القابلة للذوبان

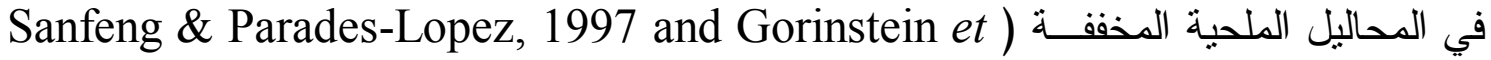
2002

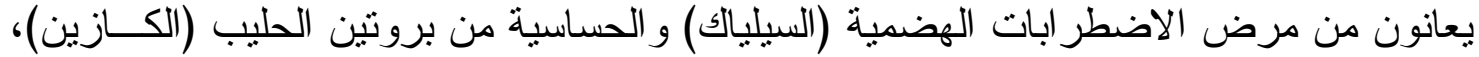

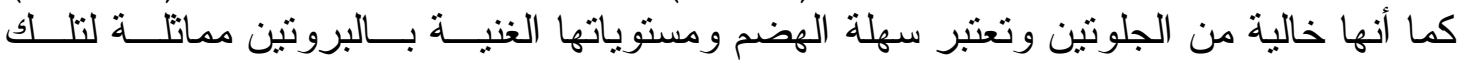
المتو اجدة في الحليب (الكازين) (Ruales and Nair, 1993)، ويعد بروتين حبوب الكينو ا غنيا

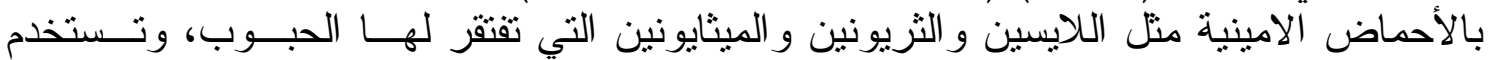

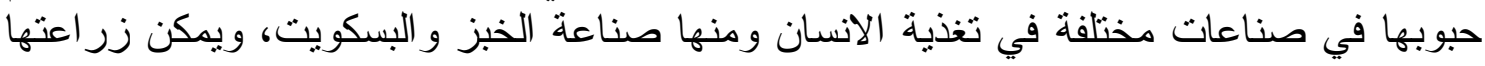
كمحصول غذاء للإنسان او الحيوان او كمحصول مئن زيتي) (Iqbal, 2015).

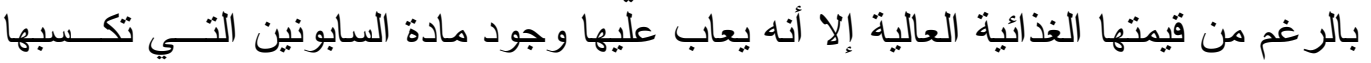

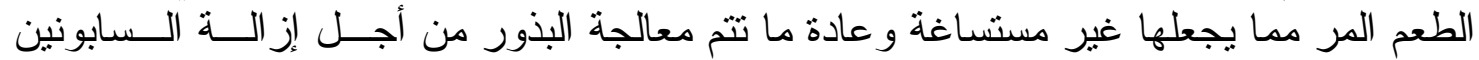

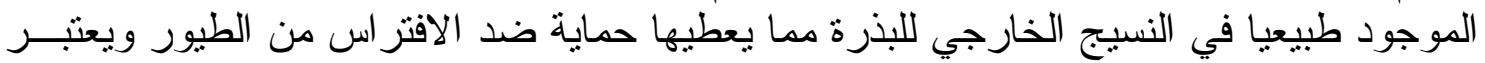

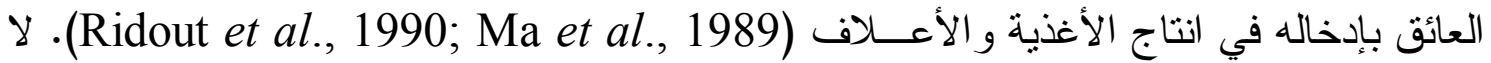

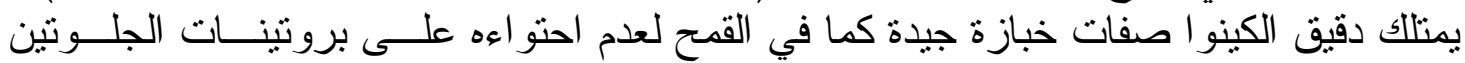

(Shewry et al., 2002)

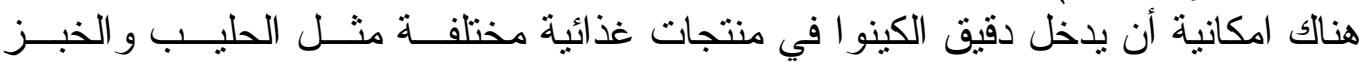

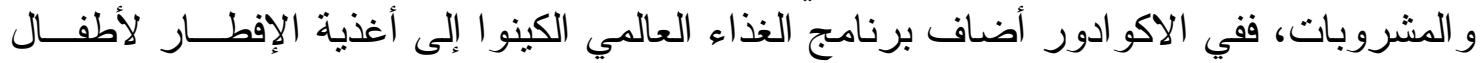

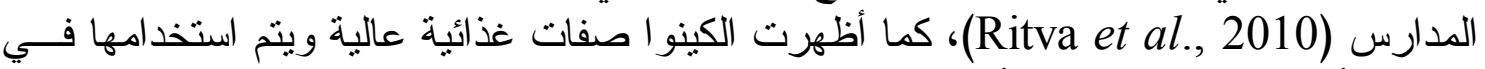

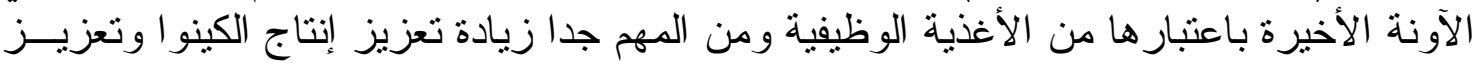

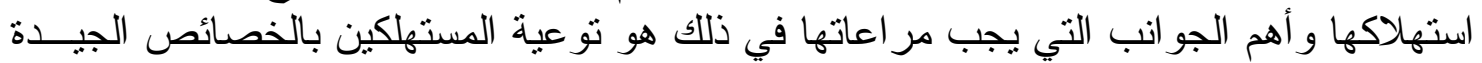

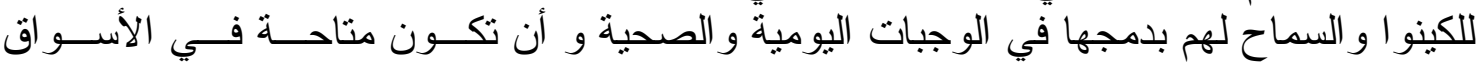

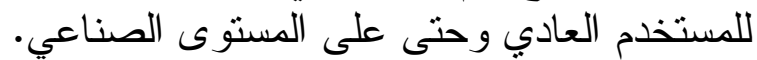

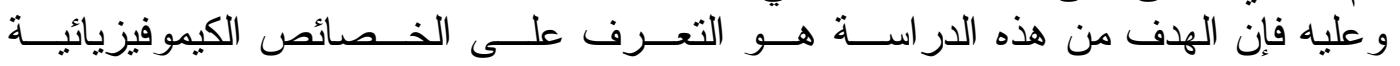

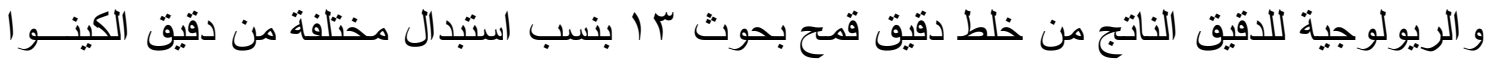
وصفات وجودة الخبز الناتج.

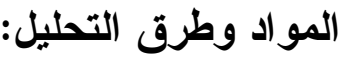
مصادر الحبوب و المواد المئ الخام -

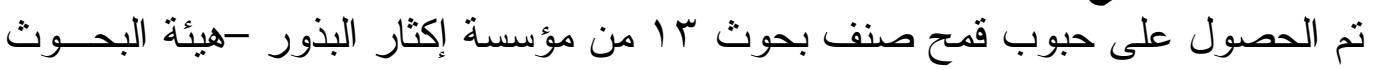

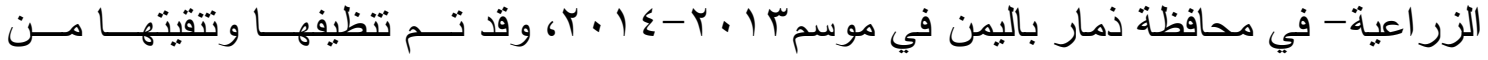

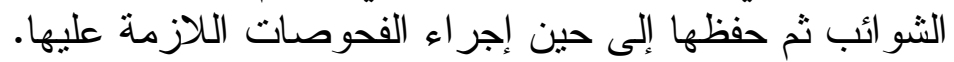
r - مصادر الكينوا تم الحصول على بذور نبات الكينو ا من هيئة البحوث الزر اعية في محافظة ذمار بــاليمن

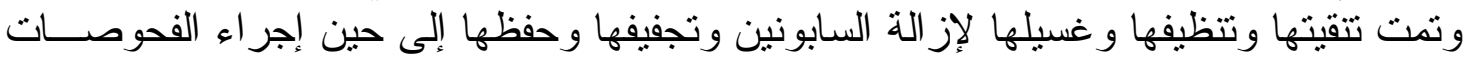
الازمة عليه. 


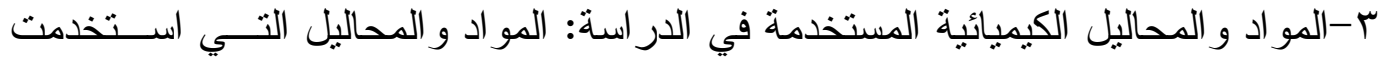

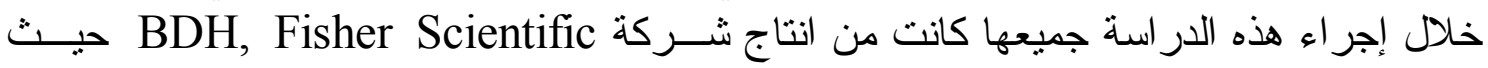

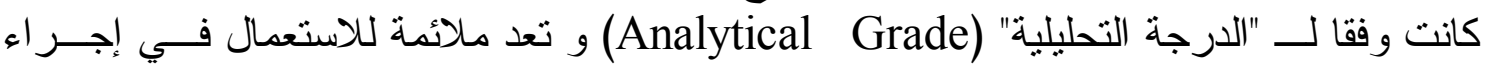

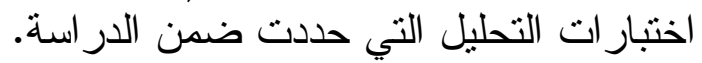

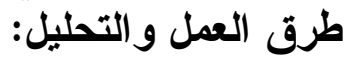

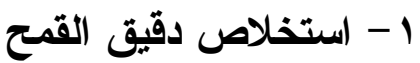

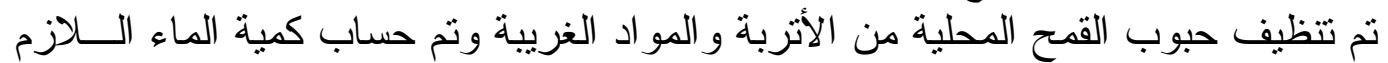

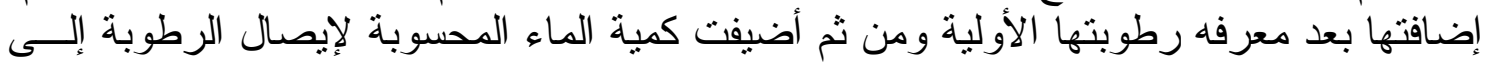

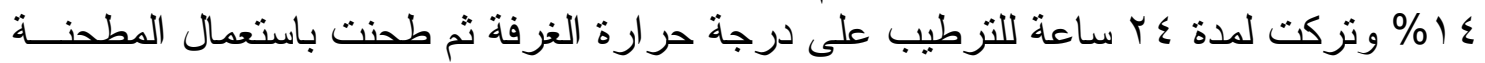

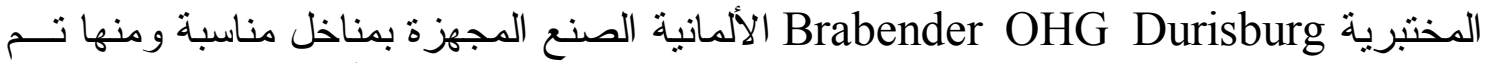

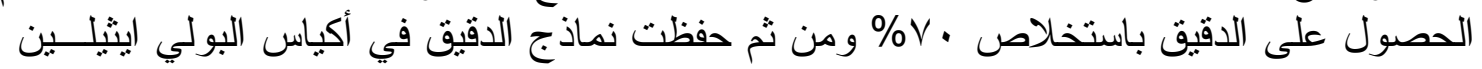

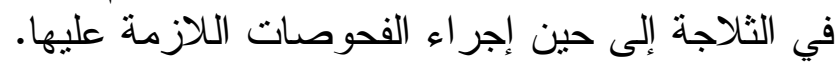

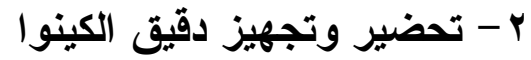

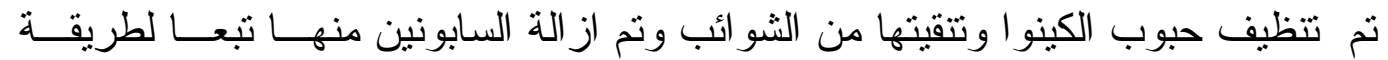

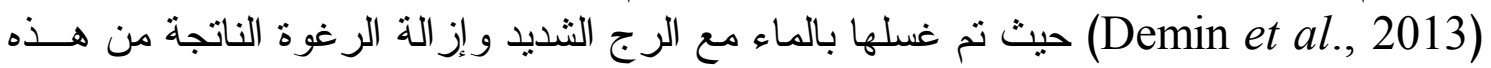

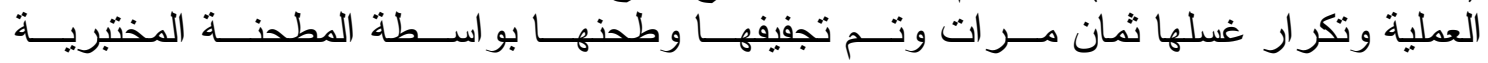
Laboratory Mill 120

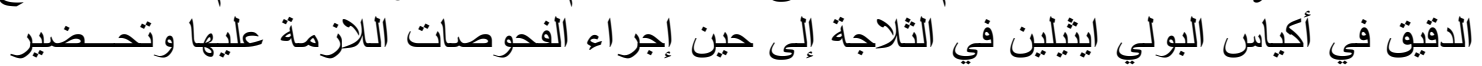

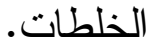
تحضير الخلطات ونسب المكونات

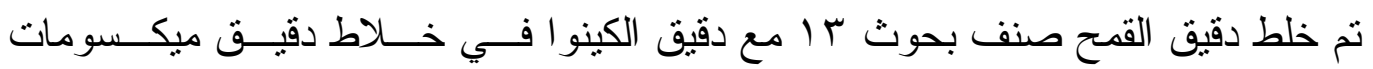

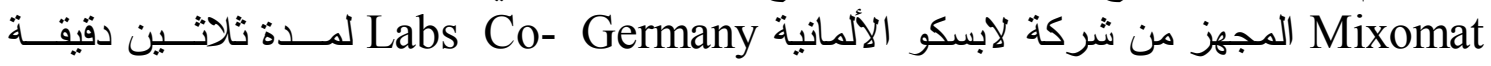

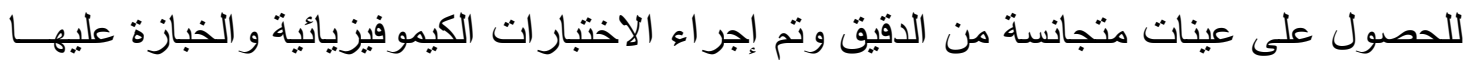

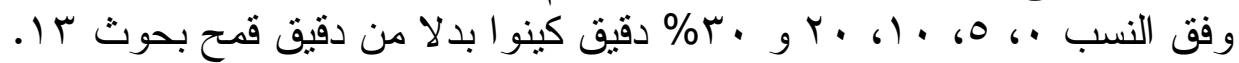

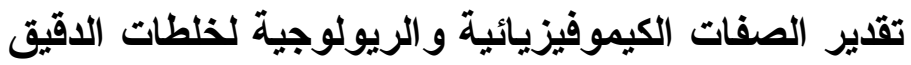

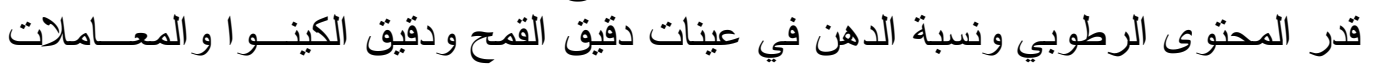

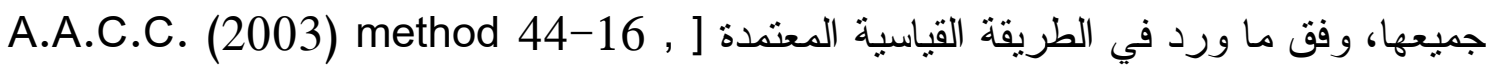

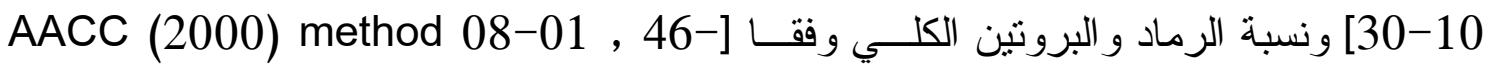

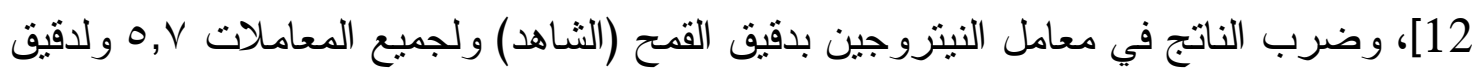

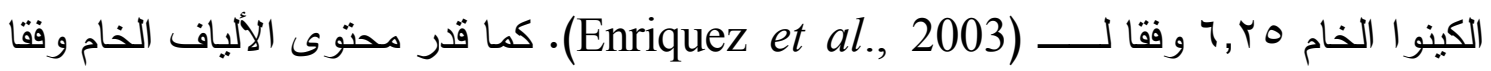
(AOAC (1984) No. 14.020)

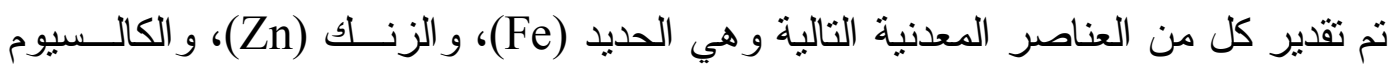

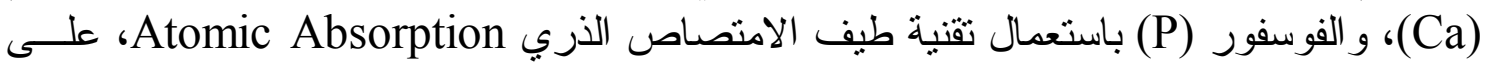

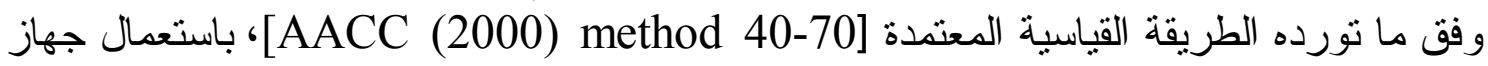

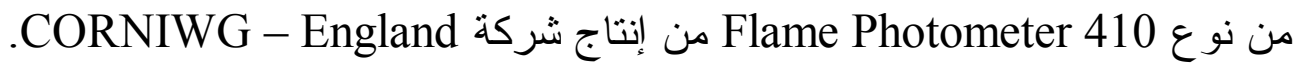

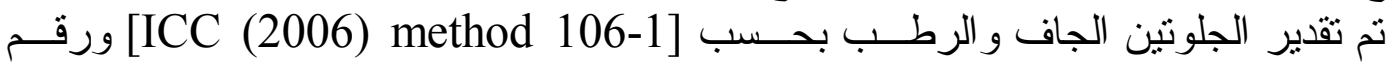

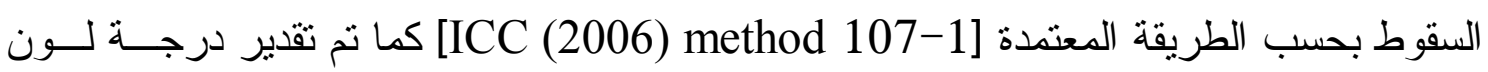
الدقيق باستخدام جهاز (Color grader series IV) المجز من شركة Satake البريطانية. 
اما الصفات الريولوجية تم تقدير ها بالفارينوجر اف وفقا [ICC (2006) method 115]. عملية الخبيز:

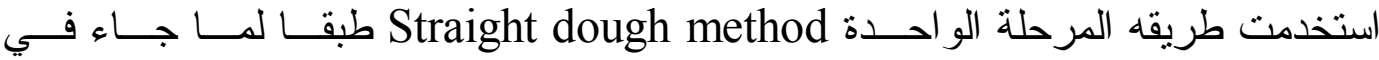
AACC (2000) method 10-10B]

التحليل الاحصائي:

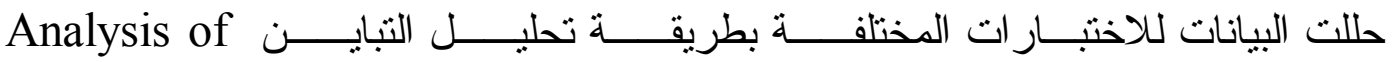
(ANOVA) variance

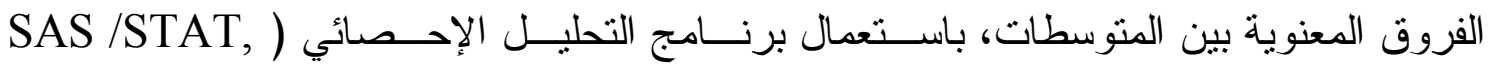
. $(2000$

النتائج والمناقشة

جدول ا ـ الصفات الكيميائية لخلطات دقيق قمح بحوث ا ا مع دقيق الكينوا

\begin{tabular}{|c|c|c|c|c|c|c|}
\hline \multicolumn{5}{|c|}{ محتوى العينة من المكون على أساس ( gm/100gm) } & \multicolumn{2}{|c|}{ نسبة الخلط } \\
\hline الألياف & 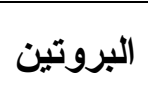 & الاهن & الرماد & الرطوبة & دقيق الكينوا & بحوثَّ 1 \\
\hline $0.62^{f}$ & $11.45^{\mathrm{c}}$ & $1.37^{f}$ & $0.73^{f}$ & $11.5^{\mathrm{ab}}$ & $0 \%$ & $100 \%$ \\
\hline $5.69^{\mathrm{a}}$ & $15.06^{\mathrm{a}}$ & $5.62^{\mathrm{a}}$ & $2.47^{\mathrm{a}}$ & $09.1^{\mathrm{d}}$ & $100 \%$ & $0 \%$ \\
\hline $0.95^{\mathrm{e}}$ & $11.63^{c}$ & $1.65^{\mathrm{e}}$ & $0.88^{\mathrm{e}}$ & $11.7^{\mathrm{a}}$ & $5 \%$ & $95 \%$ \\
\hline $1.26^{\mathrm{d}}$ & $11.81^{\mathrm{c}}$ & $1.93^{\mathrm{d}}$ & $1.03^{\mathrm{d}}$ & $11.6^{\mathrm{a}}$ & $10 \%$ & $90 \%$ \\
\hline $1.77^{\mathrm{c}}$ & $12.17^{b}$ & $2.49^{c}$ & $1.18^{\mathrm{c}}$ & $11.3^{\mathrm{bc}}$ & $20 \%$ & $80 \%$ \\
\hline $2.09^{b}$ & $12.53^{b}$ & $3.06^{b}$ & $1.33^{\mathrm{b}}$ & $11.2^{\mathrm{c}}$ & $30 \%$ & $70 \%$ \\
\hline 0.1190 & 0.5779 & 0.0455 & 0.0587 & 0.2573 & & \\
\hline
\end{tabular}

* قيم النتائج في الجدول تمنل المتوسط الحسابي لثناث مكرر ات. * قيم المتوسطات التي تحمل الحرف نفسه في العمود الو احد لا تختلف معنويا عن بعضها وفقا لاختبار أقل فرق معنوي LSD عند (P S (P).

تم تقدير المحتوى المائي و المحتوى البروتنيني و الدهني ومحتوى الرماد و الاليــاف الخــام

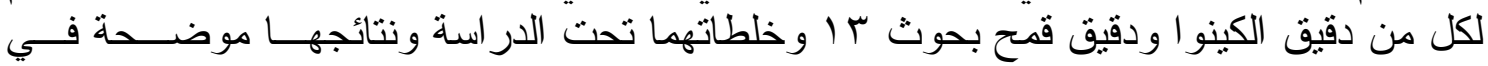

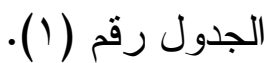

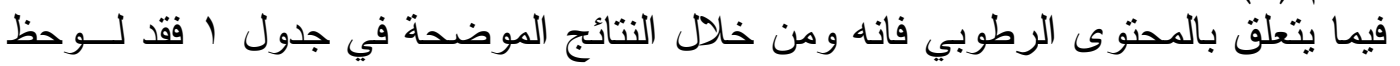

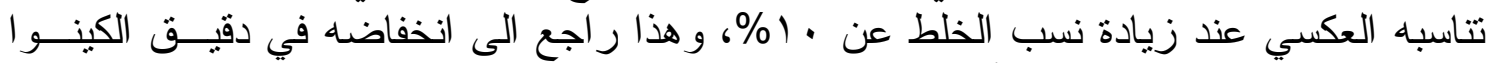

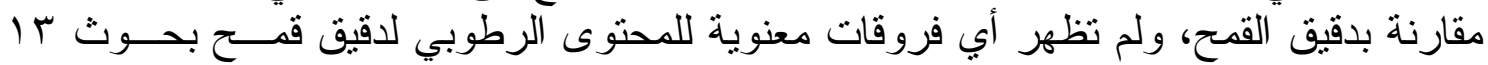

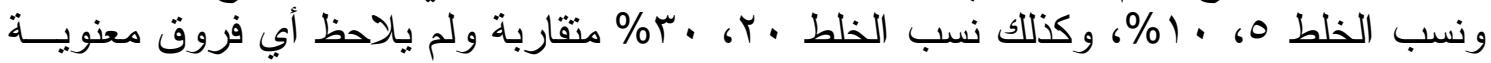
فيما بينها.

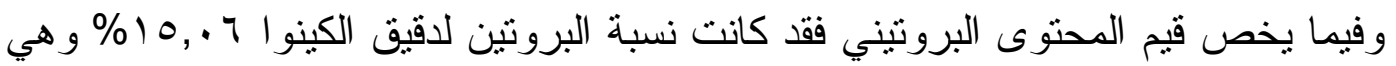

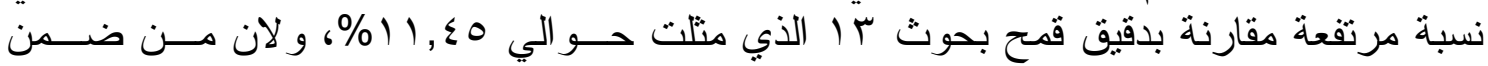
اهداف هذا البحث هو تحسين القيمة الغذائية للخبز الناتج عن طريق الإضـافات المختلفـــة لــدقيق

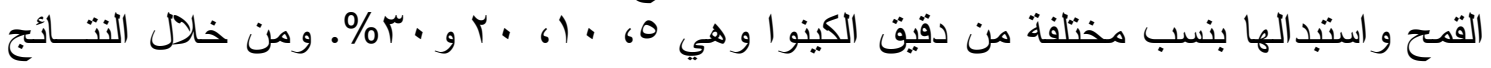


الموضحة في الجدول ا يتضح ان قيم المحتوى البروتيني لاقيق قمح بحوث بـ با ونسب الإحلال

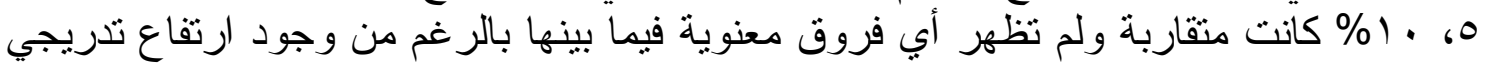

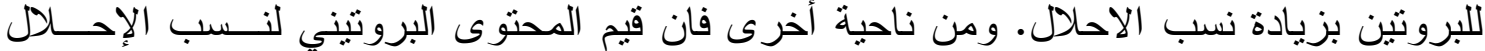

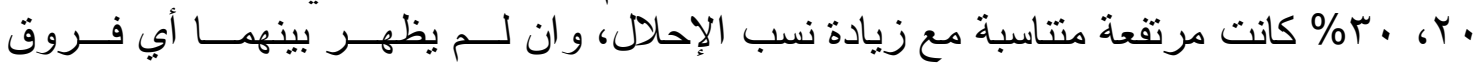

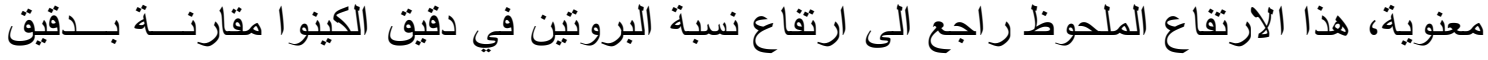

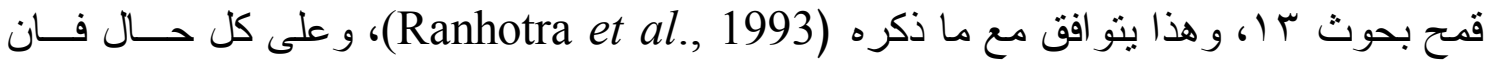

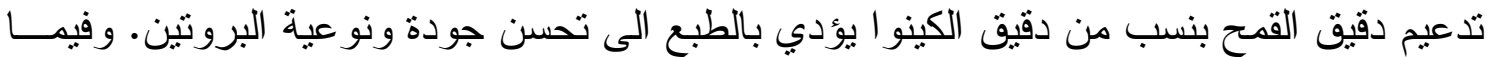

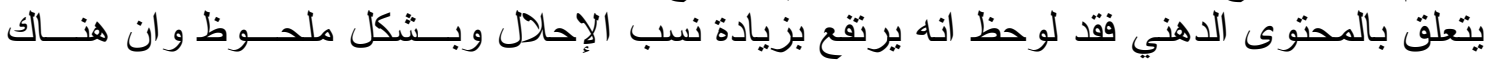

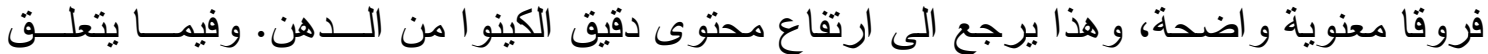

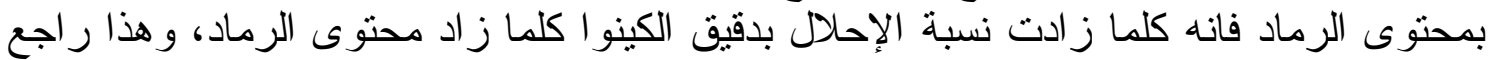

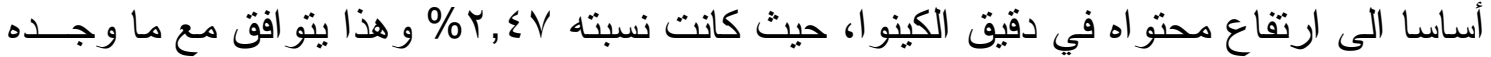

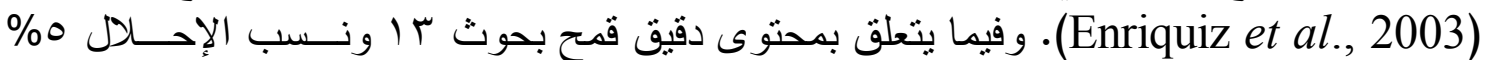

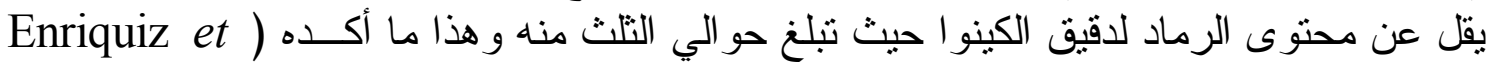

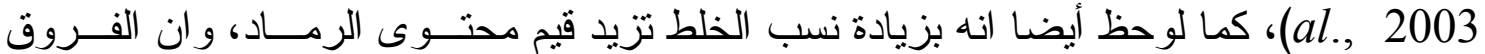

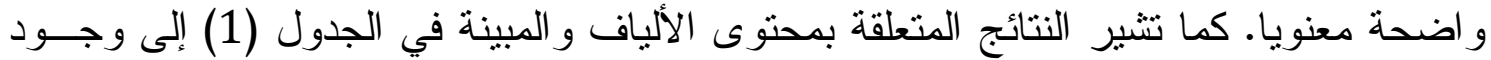

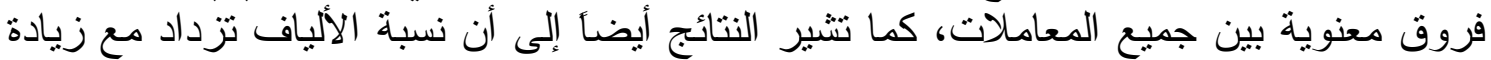

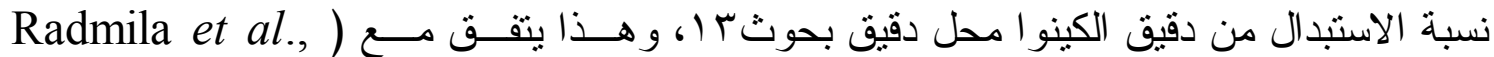
الإي 2010

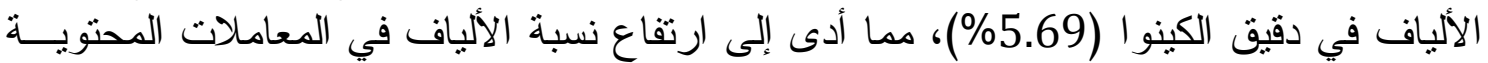
على دقيق الكينو ا بنسب منز اليدة.

جدول r ـ محتوى العناصر المعنية في خلطات دقيق قمح بحوث ا ا مع دقيق الكينوا

\begin{tabular}{|c|c|c|c|c|c|}
\hline \multicolumn{4}{|c|}{ محتوى العينة من المكون على أساس ( ppm) } & \multicolumn{2}{|c|}{ نسبة الخلط } \\
\hline فوسفور & 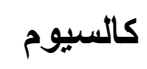 & زنتك & حديد & دقيق الكينوا & دقيق بحوث س \\
\hline $1804.0^{\mathrm{f}}$ & $258.5^{\mathrm{e}}$ & $39.2^{\mathrm{a}}$ & $160.1^{\mathrm{d}}$ & $0 \%$ & $100 \%$ \\
\hline $5391.0^{\mathrm{a}}$ & $1605.0^{\mathrm{a}}$ & $34.7^{\mathrm{a}}$ & $261.0^{\mathrm{a}}$ & $100 \%$ & $0 \%$ \\
\hline $1957.8^{\mathrm{e}}$ & $328.9^{\text {ed }}$ & $36.0^{\mathrm{a}}$ & $168.7^{\mathrm{c}}$ & $5 \%$ & $95 \%$ \\
\hline $2239.2^{\mathrm{d}}$ & $390.7^{\mathrm{d}}$ & $37.6^{\mathrm{a}}$ & $170.4^{\mathrm{c}}$ & $10 \%$ & $90 \%$ \\
\hline $2566.3^{\mathrm{c}}$ & $549.0^{c}$ & $39.7^{\mathrm{a}}$ & $184.1^{b}$ & $20 \%$ & $80 \%$ \\
\hline $2889.0^{\mathrm{b}}$ & $627.8^{\mathrm{b}}$ & $37.6^{\mathrm{a}}$ & $192.4^{\mathrm{b}}$ & $30 \%$ & $70 \%$ \\
\hline 75.7280 & 5.7545 & 6.6400 & 5.6125 & & $\mathrm{sd}$ \\
\hline
\end{tabular}

"ق قيم النتائج في الجدول تمثل المنوسط الحسابي لثلاث مكرر ات. * قيم المتوسطات التي تحمل الحرف نفسه في العمود الو احد لا نختلف معنويا عن بعضها وفقا لاختبار أقل فرق

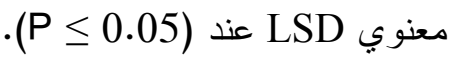

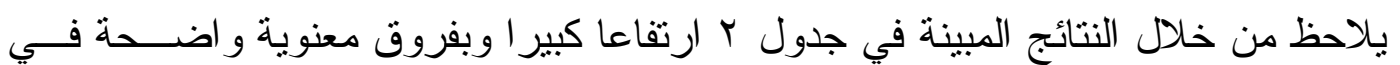

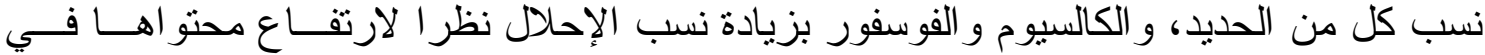

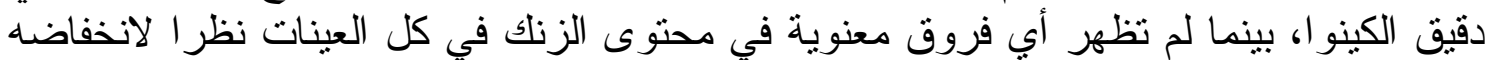

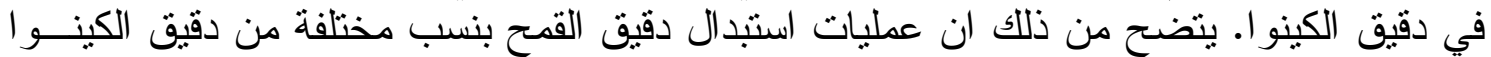
أدى الى تحسين المحتوى من العناصر المعدنية، مما يزيد المغنيات المين في الخبز الناتج. 


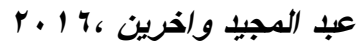

جدول r. بعض الصفات القيزيائية لخلطات دقيق قمح بحوث ا مع دقيق الكينوا

\begin{tabular}{|c|c|c|c|c|c|}
\hline \multicolumn{4}{|c|}{ الصفة } & \multicolumn{2}{|c|}{ نسبة الخلط } \\
\hline الجلوتين الجاف & الجلوتين الرطب & (وحدة لون) & رقم السقوط/ ث & الكينوا & دقيق بحوث \\
\hline $8.40^{\mathrm{a}}$ & $25.40^{\mathrm{a}}$ & $1.70^{\mathrm{e}}$ & $294^{\mathrm{d}}$ & $0 \%$ & $100 \%$ \\
\hline $8.10^{\mathrm{a}}$ & $24.80^{\mathrm{b}}$ & $5.00^{\mathrm{d}}$ & $374^{\mathrm{c}}$ & $5 \%$ & $95 \%$ \\
\hline $7.65^{b}$ & $24.30^{\mathrm{c}}$ & $6.50^{c}$ & $386^{b}$ & $10 \%$ & $90 \%$ \\
\hline $7.23^{b c}$ & $20.60^{d}$ & $8.40^{\mathrm{b}}$ & $388^{b}$ & $20 \%$ & $80 \%$ \\
\hline $6.90^{c}$ & $18.94^{\mathrm{e}}$ & $9.80^{\mathrm{a}}$ & $411^{\mathrm{a}}$ & $30 \%$ & $70 \%$ \\
\hline 0.4445 & 0.4254 & 0.1694 & 8.4552 & & Lsd \\
\hline
\end{tabular}

* قيم النتائج في الجدول تمنل المتوسط الحسابي لثنلاث مكرر ات. * قيم المنوسطات التي تحمل الحرف نفسه في العمود الو احد لا تختلف معنويا عن بعضها وفقا لاختبار أقل فرق معنوي LSD) عند (P

تم تقدير الجلوتين الجاف و الرطب وقم السقوط و الفارينوجر اف بغرض التعرف على كفاءة نسب الخلط لإنتاج الخبز، ومعرفة جودة البروتين حيث يفترض انه بارئ بارتفاع نسبة الجلوتين يكون

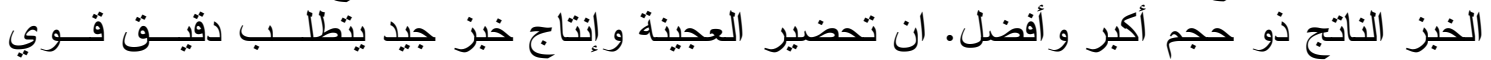

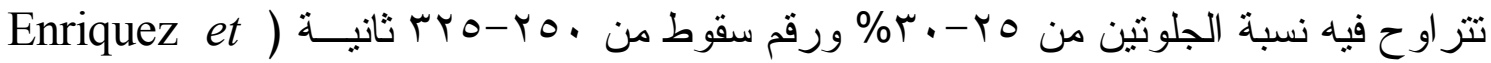
.(al., 2003

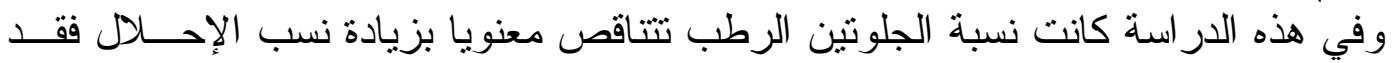

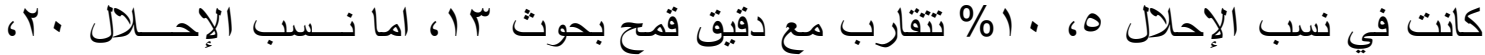

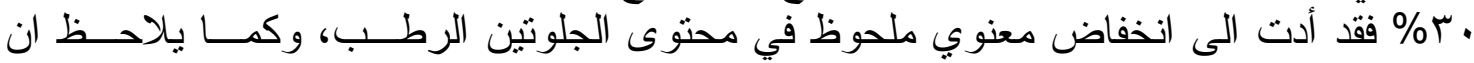

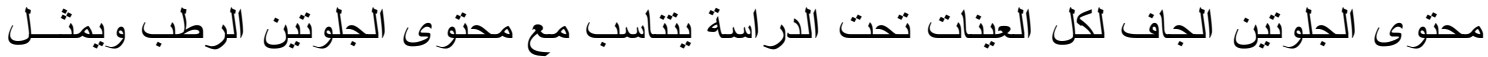
تقريبا الثلث، وهذا يتو افق مع ما ذكره (Enriquez et al., 2003).

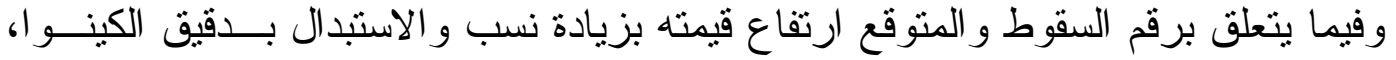

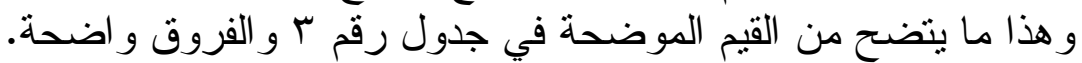

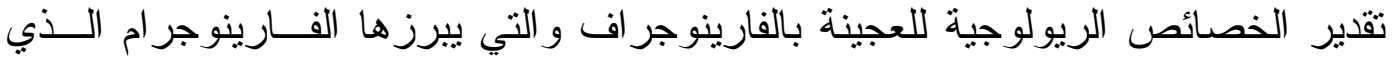
يوضح سلوك العجينة خلال عملية العجن و التي تتمنل بالمرونة و المطاطية للعجينة اثتاء مرورها في الخلط المستمر عند درجة حرارة ثابتة (Quaglia, 1991). ومن خلال النتائج الموضحة في الجدول (ع) ينتين ان قيم الخصائص الريولوجية للعجينة

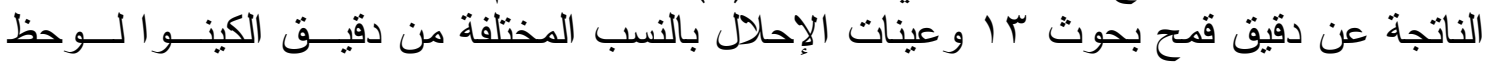
ارتفاع تدريجي لقيم الامتصاصية وتطور العجينة بزيادة نسبة الاحلال بدقيق الكينو ا. 
جدول ؛. الصفات الريولوجية لخلطات دقيق قمح بحوث ا 1 مع دقيق الكينوا

\begin{tabular}{|c|c|c|c|c|c|}
\hline \multicolumn{4}{|c|}{ مؤشرات الفارينوجر اف } & \multicolumn{2}{|c|}{ نسبة الخلط } \\
\hline النعومة/BU & الثباتية/ دقيقة & تطور العجينة/ دقيقة & الامتصاصية \% & دقيق الكينوا & دقيق بحوث \\
\hline $211^{\mathrm{b}}$ & $2.30^{\mathrm{b}}$ & $3.50^{\mathrm{bc}}$ & $68.20^{c}$ & $0 \%$ & $100 \%$ \\
\hline $182^{\mathrm{d}}$ & $2.90^{\mathrm{a}}$ & $3.90^{\mathrm{a}}$ & $70.90^{\mathrm{b}}$ & $5 \%$ & $95 \%$ \\
\hline $202^{\mathrm{c}}$ & $2.20^{\mathrm{b}}$ & $3.60^{\mathrm{abc}}$ & $71.30^{\mathrm{b}}$ & $10 \%$ & $90 \%$ \\
\hline $241^{\mathrm{a}}$ & $1.85^{\mathrm{c}}$ & $3.40^{\mathrm{c}}$ & $72.50^{\mathrm{ab}}$ & $20 \%$ & $80 \%$ \\
\hline $215^{\mathrm{b}}$ & $1.80^{\mathrm{c}}$ & $3.80^{\mathrm{ab}}$ & $73.20^{\mathrm{a}}$ & $30 \%$ & $70 \%$ \\
\hline 3.5464 & 0.3080 & 0.3546 & 1.6454 & & Lsd \\
\hline
\end{tabular}

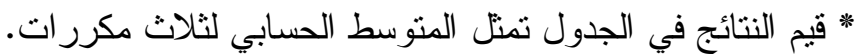

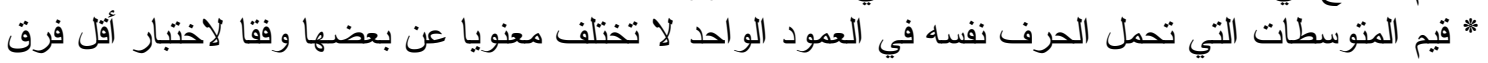
منوي LSD (P

ومن ناحية أخرى، أظهرت المعاملة 0\% أفضل درجة ثباتية ودرجة نعومة للعجينة مدــا يـشير

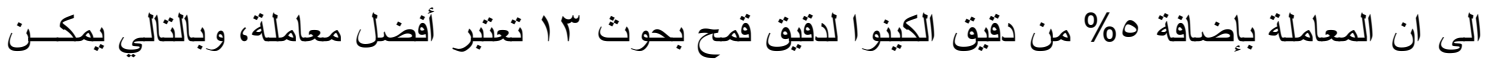

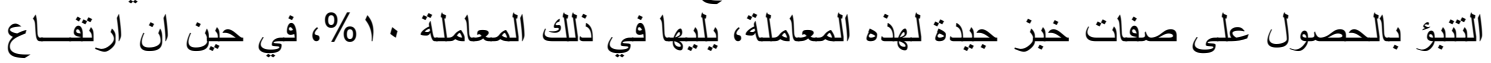

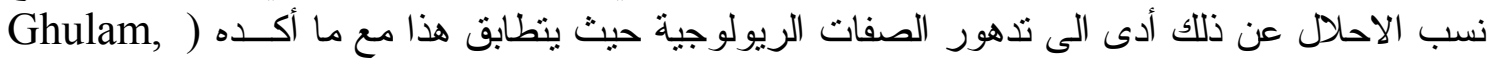

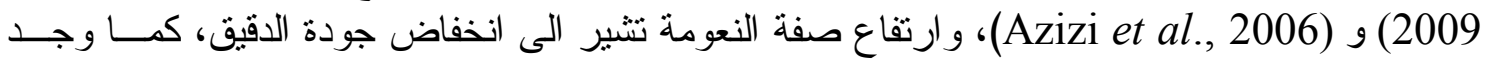
(Williams et al., 1988)

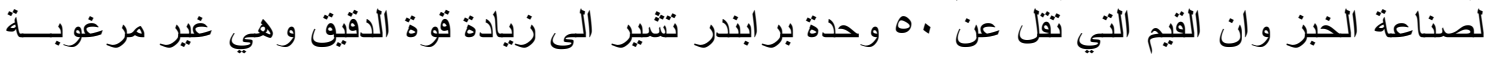

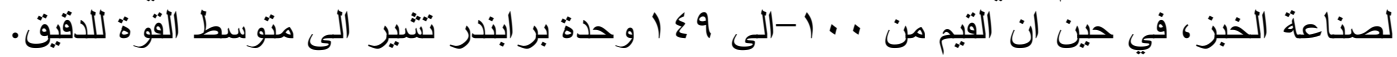

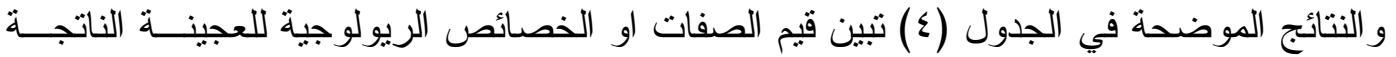

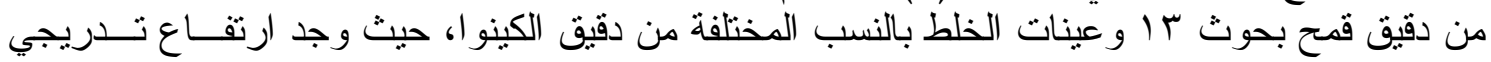

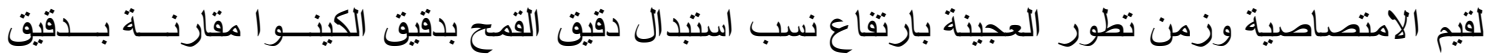

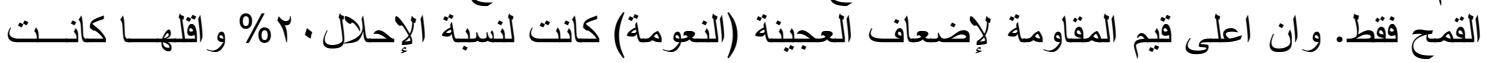

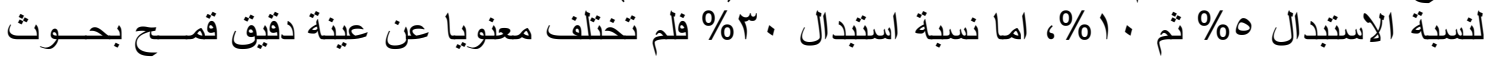

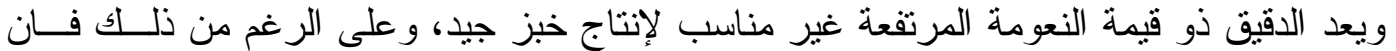

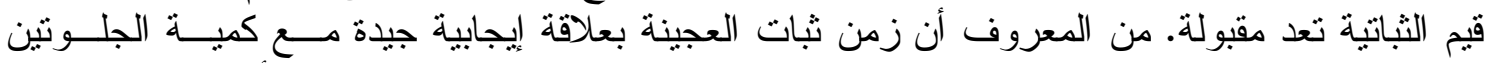

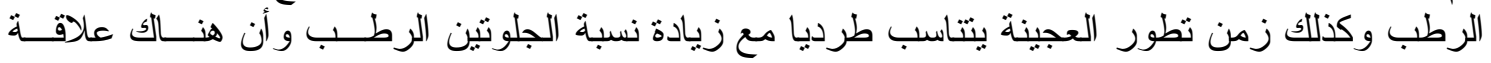

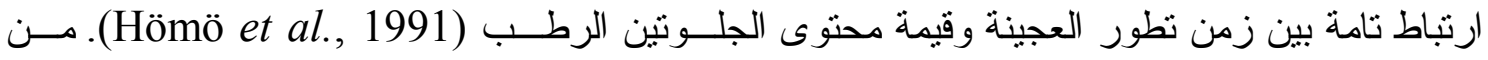

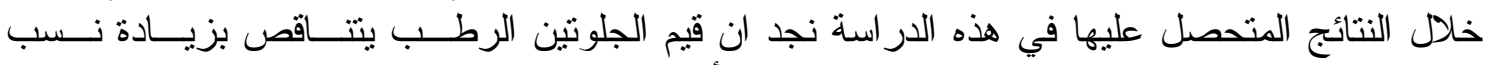

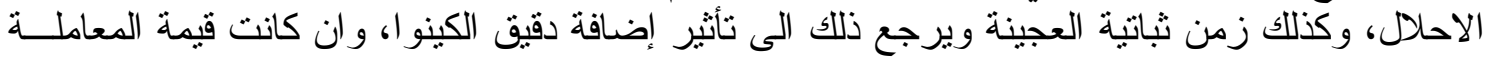
\% مختلفة، و هذه النتائج تنفق جزئيا مع وجده (Enriquez et al.,2003). 


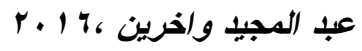

جدول ه. الصفات الفيزيائية للخبز الناتج من خلطات دقيق قمح بحوث ا ا مع دقيق الكينوا

\begin{tabular}{|c|c|c|c|c|}
\hline \multicolumn{3}{|c|}{ الصفات الفيزيائية } & \multicolumn{2}{|c|}{ نسبة الخلط } \\
\hline الحجم النوعي سمَ"/جم & حجم الخبز/سم" & وزن الخبز/جم & دقيق الكينوا & دقيق بحوث 1 I \\
\hline $3.60^{\mathrm{a}}$ & $315.20^{\mathrm{a}}$ & $87.30^{\mathrm{a}}$ & $0 \%$ & $100 \%$ \\
\hline $3.45^{b}$ & $301.50^{b}$ & $87.40^{\mathrm{a}}$ & $5 \%$ & $95 \%$ \\
\hline $3.32^{\mathrm{c}}$ & $288.90^{\mathrm{c}}$ & $87.03^{b}$ & $10 \%$ & $90 \%$ \\
\hline $2.80^{d}$ & $242.36^{\mathrm{d}}$ & $86.25^{\mathrm{c}}$ & $20 \%$ & $80 \%$ \\
\hline $2.47^{\mathrm{e}}$ & $214.00^{\mathrm{e}}$ & $86.80^{b}$ & $30 \%$ & $70 \%$ \\
\hline 0.0182 & 2.2040 & 0.2539 & \multicolumn{2}{|c|}{ *Lsd } \\
\hline
\end{tabular}

" قيم النتائج في الجدول تمثلل المتوسط الحسابي لثناث مكررات.

* قيم المتوسطات التي تحمل الحرف نفسه في العمود الواحد لا لا تختلف معنويا عن بعضها وفقا لاختبار أقل

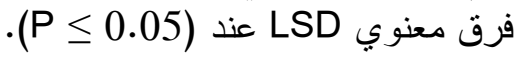

ومن النتائج الموضحة في الجدول (0) نجد ان هناك علاقة عكسية بين قيم الحجم النوعي بلتي

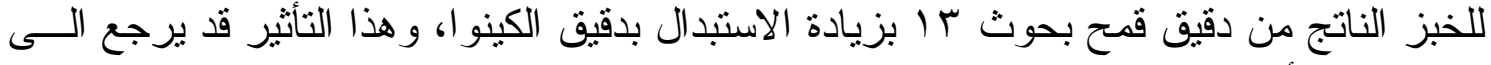

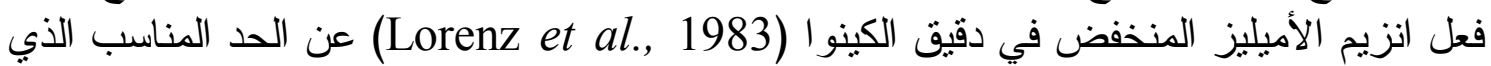

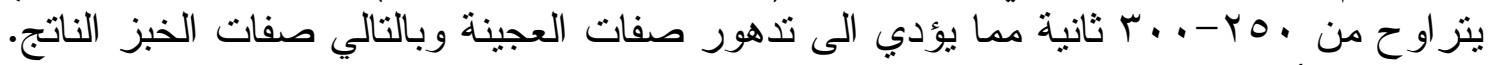

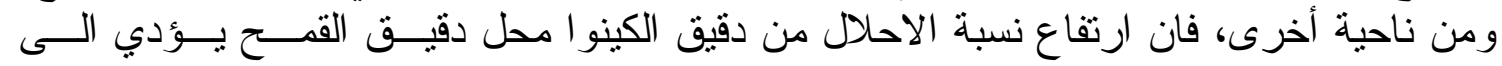

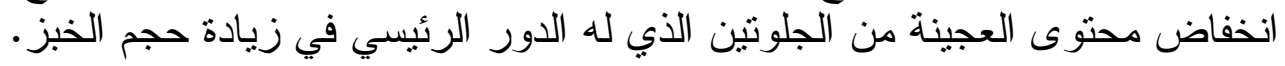

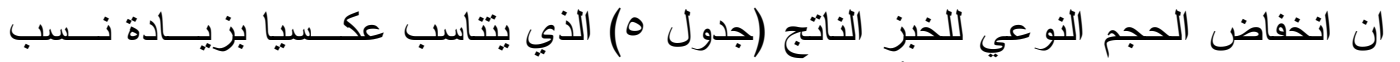

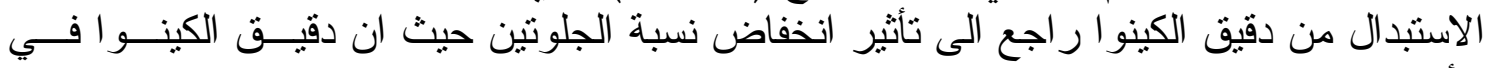

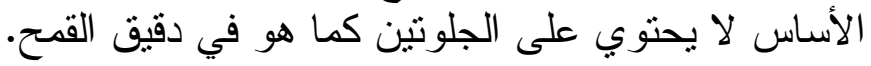

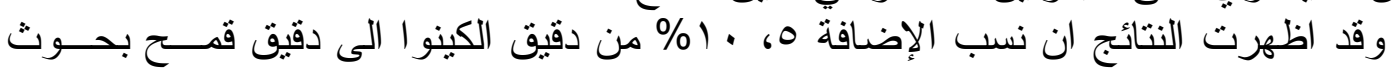

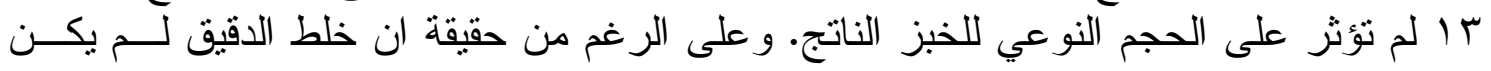

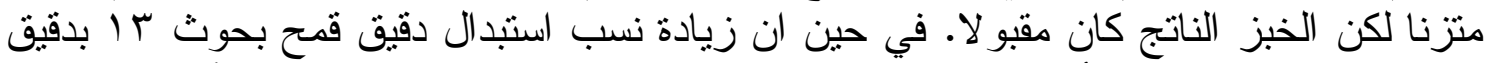

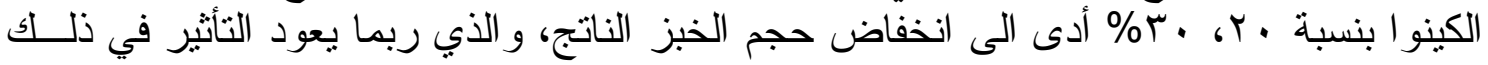

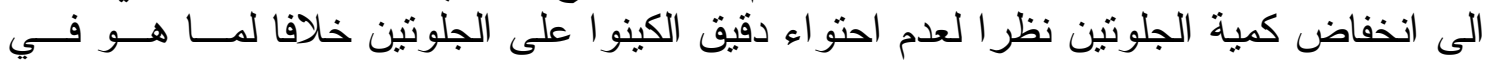

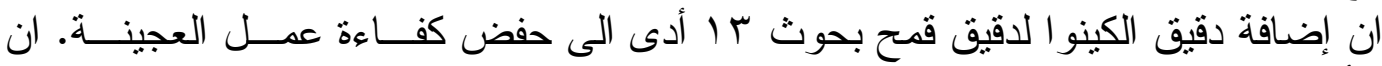

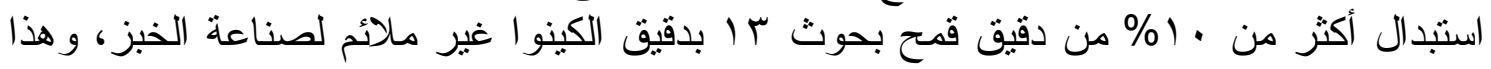

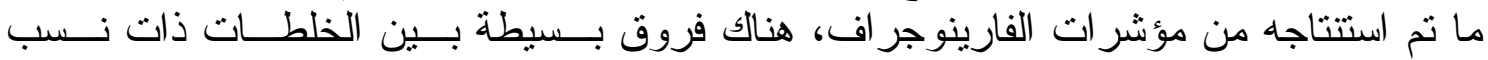

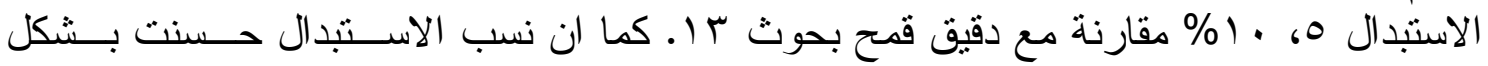

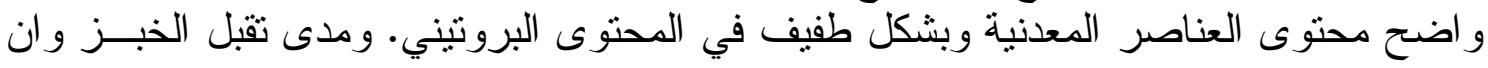

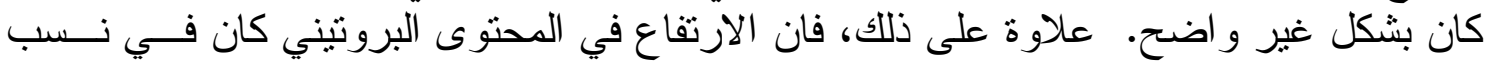
الإحلال ه، • 1\% عان

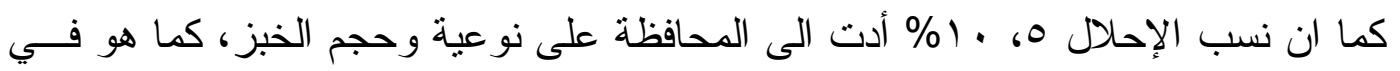
الخبز الناتج من دقيق قمح بحوث لـ الاحل 


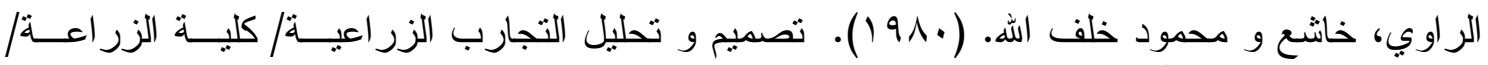
جامعة الموصل/ العراق.

A.O.A.C. (1984). "Official Methods of Analysis". Association of Official Analytical Chemists.

AACC (2000). Approved Methods of the American Association of Cereal Chemists, $10^{\text {th }}$ ed. Methods 08-01, 10-10B, 40-70, 46-12. AACC St. Paul, $\mathrm{MN}$.

AACC. (2003). Approved Method of the American Association of Cereal Chemists. St. Paul, Minnesota. U.S.A.

Azizi, M.H., Sayeddin S.M., and Payghambardoost, S.H. (2006). Effect of Flour Extraction Rate on Flour Composition, Dough Rheological Characteristics and Quality of Flat Bread. J. Agric. Sci. Technol. (8):323-330.

Bajkai, T., Popineau, Y., Tömösközi, S., and Daniel, A. (1996). Determination of emulsifying properties by conducto metric methods: Comparison and evaluation. In: Proceeding 75 Years of Cereal Chemistry and Food Quality Control, Jubilee Symposium of Dpt. of Biochemist and Food Technology Technical University of Budapest, 06.17.-06.18. Budapest.

Been, M.M., and Fellers D.A. (1982). Composite breads in Bolivia: Technical Aspects. In: Proceeding 7th World Cereal and Bread Congress, Prague: 859-864.

Caperuto, L.C., Amaya-Farfan, J., and Camargo, C.R.O. (2001). Performance of quinoa (Chenopodium quinoa Willd) fluorine the manufacture of glutenfree spaghetti. J. of the Sci. of Food and Agric., 81: 95-101.

Chauhan, G. S.; Zillman, R. R. and Eskin, N. A. M.(1992). Dough mixing and breadmaking properties of quinoa-wheat flour blends. Int. J. Food Sci. Technol. 27:701-705.

Demin, M. A.; Vucelić-Radović, B. V.; Banjac, N. R.; Tipsina N. N. and Milovanović M. M. (2013). Buckwheat and Quinoa seeds as supplements in wheat bread production. Hem. ind. 67 (1): 115-121.

Enriquez, N. M. Peltzer, A. Raimundi, V. Tosi, and L.M. Pollio (2003). Characterization of the wheat and quinoa flour blends in relation to their bread making quality. J. Argent. Chem. Soc. 91(4-6):47-54.

Ghulam, Mueen-uddin. (2009). Effect of Flour Extraction Rate on Flour Composition, Dough Rheological Characteristics and Quality of Flat Bread. J. Agric. Sci. Technol. 8: 323-330.

Gorinstein, S., Pawelzik, E., Delgado-Licon, E., Haruenkit, R., Weisz, M., and Trakhtenberg, S. (2002). Characterization of pseudocereal and cereal proteins by protein and amino acid analyses. J. of the Sci. of Food and Agric., 82: 886-891.

Hofmanová, T., Hrušková, M., and Švec, I. (2014). Evaluation of wheat/nontraditional flour composites. Czech J. Food Sci., 32: 288-295.

Hömö, L.; Pietilä, E. and Salo, Y. (1991). Suitability of Gluten Index Method for Evaluation of Wheat Flour Quality. Ann. Agric. Fenn. 30, 191-198. 
ICC. (2006). Standard No. 106(Gluten), 107 (Falling Number); Standard No.115(Farinograph). Standard Methods of the ICC, International Association for Cereal Science and Technology. Vienna, Austria.

Iqbal, M. A. (2015). An Assessment of Quinoa (Chenopodium quinoa Willd.) Potential as a Grain Crop on Marginal Lands in Pakistan. Am-Euras. J. Agric. \& Environ. Sci., 15 (1): 16-23, 2015

Konishi, Y., Hirano, S., Tsuboi, H., and Wada, M. (2004). Distribution of minerals in quinoa (Chenopodium quinoa Willd) seeds. Biosci. Biotechnol. Biochem. 68:231-234.

Koziol, M. J. (1992). Chemical composition and nutritional evaluation of quinoa (Chenopodium quinoa Willd). Journal of Food Composition and Analyses. 5: 35-68.

Lorenz, K.; Roewe-Smith, P.; Kulp, K.; Bates, L.(1983). Preharvest Sprouting of Winter Wheat. II. Amino Acid Composition and Functionality of Flour and Flour Fractions. Cereal Chem., 60, 360.

Lorenz K., and Coulter, L. (1991). Quinoa flour in baked products. Plant Foods for Human Nutrition, 41: 213-223.

Ma, W.W., Heinstein, P.F., and McLaughlin, J.L. (1989). Additional toxic, bitter saponins from the seeds of Chenopodium quinoa. J. of Natural Products 52: 1132-1135.

Park, S. H. and Morita, N. (2005). Dough and breadmaking properties of wheat flour substituted by $10 \%$ with germinated quinoa flour. Food Sci. and Technology International, 11, (6), 471-476.

Quaglia, G. (1991). CienciayTechnologia de la panificaciony, 2nd ed., Acribia: Zaragoza, Cap 2.

Radmila, Stikic. Djordje, Glamoclija., Mirjana, Demin., Biljana, VucelicRadovic., Zorica, Jovanovic., Dusanka, Milojkovic-Opsenica., Sven-Erik, Jacobsen., and Mirjana, Milovanovic. (2012). Agronomical and nutritional evaluation of quinoa seeds (Chenopodium quinoa Willd) as an ingredient in bread formulations. J. of Cereal Sci., 55: 132-138.

Ranhotra, G., Gelroth, J., Glaser, B., Lorenz, K., and Johnson, D. (1993). Composition and protein nutritional quality of quinoa. Cereal Chem. 70(3): 303-305.

Ridout, C., Price, K., and Fenwick, R. (1990). Quinoa. Nutrition and Food Science 120: 5-7.

Ritva, A. M.; Repo-Carrasco-Valencia., Christian, R., Encina, Maria, J., Binaghi, Carola, B., Grecob, and Patr'icia A. Ronayne de Ferrer. (2010). Effects of roasting and boiling of quinoa, kiwicha and ka niwa on composition and availability of minerals in vitro. J. Sci. Food \& Agric. 90: 2068 - 2073.

Ruales, J., and Nair, B. M. (1993). Content of fat, vitamins and minerals in quinoa (Chenopodium quinoa Willd.) seeds. Food Chem. 48: 131-136.

Sanfeng, Chen., and Parades-Lopez, O. (1997). Isolation and characterization of the 11S globulin from amaranth seeds. J. of Food Biochemis., 21: 53-65.

SAS/STAT. (2000). User's Guide Statistical Analysis System Institute. Inc. Cary. N.C. 
Shewry, P.; Halford, N.; Belton, P. and Tatham, A. (2002). The structure and properties of gluten: An elastic protein from wheat grain. Phil. Trans. R. Soc. Lond. B. 357: 133-142.

Tömösközi, S., Popineau, Y., Bajkai, T., and Lasztity, R. (1994). Determination of foaming properties of food proteins by conductometric methods-A comparative study. Proceedings $1^{\text {st }}$ International Conference on Food Physics. J. of Food Physics (Suppl.): 99-102.

Williams, P., El-Hramein, F. J., Nakkoul, H., and Rittawi, S. (1988). Crop quality evolution methods and guidelines, international center for agriculture research in the dry areas (ICARDA). Aleppo, Syria.

Wright, K., Pike, O., Fairbanks, D., and Huber, C. (2002). Composition of Atriplex hortensis, sweet and bitter Chenopodium quinoa seeds. J. Food Sci. 67(4): 1383-1385. 


\title{
Characteristics and Bread-Making Quality of Wheat and Quinoa Flour Blends
}

\author{
Abdulmageed Bagash Abdullah ; Jalal Ahmed Fadle and Khaled \\ Mohammed Assaj
}

Dept. Food Scie. \& Tech., Faculty of Agric. Sana'a University. Yemen

\begin{abstract}
This study was carried out to investigate the possibility of making molded bread of quinoa and wheat flour blends. Wheat flour replaced and mixed with 5, 10,20 and $30 \%$ of quinoa flour. Physiochemical characteristics and properties of these blends and bread making were evaluated and analyzed. The chemical composition of quinoa and wheat flours and their blends were determined via evaluation of protein, fat, moisture, ash and fiber contents. In addition, mineral elements (Iron, zinc, calcium and phosphorus), percent of wet and dry gluten, and falling number of quinoa and wheat flours were determined. Also, Farinogram parameters were studied to investigate some rheological properties of blends dough.

Obtained results showed positive relationship between content values of ash, protein, fat and fiber, and the percentage of quinoa flour. Higher values of mineral elements were recorded as the percent of quinoa flour increased, except zinc which was non-significant in all samples. Increasing amounts of quinoa flour lessened and reduced strong and extensible dough, whereas, wet and dry gluten, development time and stability of dough decreased as the percentages of quinoa flour increased.

Molded bread was prepared using straight dough method in order to evaluated bread specific volume and sensory characteristics. The results showed fewer differences in bread specific volume, between samples prepared from wheat flour or those with 5 and $10 \%$ quinoa flour blends. Results showed that blends with 5 or $10 \%$ of quinoa flour had good properties to make molded bread and had satisfactory and acceptable organoleptic evaluation.
\end{abstract}

Keywords: Quinoa, Gluten, Physiochemical, Rheological, molded bread. 